\title{
Preparation and characteristics of the sulfonated chitosan derivatives electrodeposited onto 316 stainless steel surface
}

\author{
Ye Huang a , Guangjia Peng ${ }^{a}$, Bin Chen ${ }^{a}$, Ping Yong ${ }^{a}$, Nan Yao ${ }^{a}$, Liming Yang ${ }^{a}$, Rogério \\ P. Pirraco ${ }^{b}$, Rui L. Reis ${ }^{c}$ and Jie Chen ${ }^{a}$
}

aDepartment of Chemical Engineering and Technology, School of Environmental and Chemical Engineering,

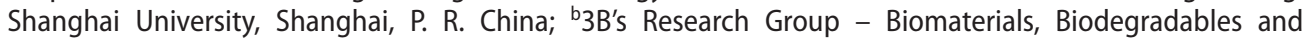
Biomimetics, University of Minho, Headquarters of the European Institute of Excellence on Tissue Engineering and Regenerative Medicine, Guimarães, Portugal; ICVS/3B's - PT Government Associate Laboratory, Guimarães, Portugal

\begin{abstract}
In order to ameliorate the properties of corrosion resistance and achieve applications in anti-biofouling of $316 \mathrm{~L}$ stainless steel (SS), a sulfated derivative of chitosan was deposited onto stainless steel surface by an electrochemical method. In detail, chitosan-catechol (CS-CT) was synthesised in the hydrochloric acid solution by the Mannich reaction and then electrodeposited on the surface of the polished 316L stainless steel. The chitosan-catechol deposited SS sample was further modified with maleic anhydride and sulfite. The grafting progress was monitored by FTIR, UV spectrophotometer and X-ray photoelectron spectroscopy. Hydrophilicity and corrosion resistance of modified SS were characterized by water contact angle measurements, Tafel curves and electrochemical impedance spectroscopy. The morphology of the SS surface before and after the modification was investigated by atomic force microscopy and scanning electron microscope. Further, the anti-biofouling performance in terms of the anti-adsorption protein and anti-bacteria effects of all modified SS samples were estimated, and the modified $316 \mathrm{~L}$ exhibits the capability of lower protein adsorption and improved antibacterial effect.
\end{abstract}

\section{ARTICLE HISTORY}

Received 20 July 2017

Accepted 16 November 2017

\section{KEYWORDS}

Chitosan; electrodeposition; surface modification; stainless steel; antibiofouling

\section{Introduction}

Stainless steel, especially austenitic stainless steel, has been used widely in the medical metal materials owing to the excellent properties of comprehensive mechanical [1]. The 316L stainless steel, a typical austenitic stainless steel, is relatively inexpensive and a common metallic materials for the medical artificial joint [2]. However, the stainless steel implant may give rise to some problem about pitting, crevice corrosion and fretting corrosion in physiological environments and release some hazardous metal ions, which may lead to

CONTACT Jie Chen jchen@shu.edu.cn

(1) Supplemental data for this article can be accessed at https://doi.org/10.1080/09205063.2017.1409047 
patients' immune response and inflammation [3]. Furthermore, fibrous cysts tend to be formed around stainless steel implants after prolonged use, increasing the risk of repulsion by the surrounding tissue [4]. Therefore, surface modification of the stainless steel has become an important issue for ameliorating biocompatibility and corrosion resistance of medical implant materials.

As for corrosion, it is caused by the physicochemical interactions between metallic material and the environment [5]. In detail, the electrochemical corrosion in metal material is a chemical reaction involving the transfer of electrons from zero valent metal to an external electron acceptor, leading to the release of the metal ions into the surrounding medium and deterioration of the metal [6]. Given this condition, the corrosion resistance of stainless steel can be improved significantly by modifying their surfaces with polymers, organic molecules, or inorganic coatings [3,4,6-8].

Based on the above discussions, how to design a more effective and practical stability of coating layer on 316L SS with a simple method is an open question. Guo and his co-workers selected the iron-based AGET ATRP strategy to conduct the SI-ATRP of polyethylene glycol methacrylate (PEGMA) on the 316 L SS surface [2]. The morphology of the SS surface was significantly altered after grafting and the anti-coagulative properties toward ACD blood were enhanced after the PEGMA modification of SS relative to those of the bare SS. Actually, using use natural material as an inspiring framework for the development of novel products to modify the surface of the metallic material is not new. Liu provided some primary results on the effects of the anti-adhesion and anti-bacteria approaches in membrane anti-biofouling performance, which employed a chitosan-based membrane as the base membrane [9]. Huang made the stainless steel coated with a layerby-layer structure of hyaluronic acid and heparin loaded with sirolimus to suppress the thrombosis and to reduce the release rate of sirolimus [10].

Heparin immobilized polymers have been reported for the ability to improve hemocompatibility because of the bioactivity of grafted heparin [11-14]. To produce a more durable anti-coagulant surface, modification of materials by incorporating sulfonate groups, the so-called heparin-like materials (heparinoid), has also been investigated by many investigators [15-17]. The term heparan sulphate has been traditionally used to describe heparin-like byproducts of the industrial preparation of heparin from animal tissues such as bovine lung and pig mucosa $[18,19]$. In this study, we chose Chitosan and Catechol to make heparin-like structures.

Chitosan, an amino polysaccharide containing with 1, 4 D-glucosamine and $\mathrm{N}$-acetyl glucosamine, is a product derived from $\mathrm{N}$-deacetylation of chitin in presence of hot alkali [20]. As a natural polymer, chitosan has already been thoroughly investigated during the past decades in the field of biomedical application due to its inherent properties such as biodegradability, low toxicity, mucoadhesion, bacteriostatic and fungistatic activity, the presence of reactive functional groups, and anti-thrombogenic properties [21]. Because of the stable crystalline structure, chitosan is normally insoluble in water, while soluble in dilute aqueous acidic solutions below its $\mathrm{pKa} \sim 6.3$, in which amine $\left(-\mathrm{NH}_{2}\right)$ groups in glucosamine units are converted into the soluble protonated form $\left(-\mathrm{NH}_{3}^{+}\right)[22,23]$. Moreover, chitosan can be modified with maleic anhydride and sodium sulfite to ameliorate anti-biofouling performance. It is contributed to the fact from previous work that negatively charged surface has been recognized to be less prone to bio-adhesion than the positively charged surface $[24,25]$. 
Catechol, as an electrochemically active molecule that first was distilled from the catechu extract, can be electrodeposited for modification of metal or stainless steel materials [26]. Forming a catechol thin film with electrodepositing techniques has been achieved in the past research [27]. Moreover, catechol can also been applied in the biomedical field for its antibacterial property [28].

The surface modification of bulk material plays important roles in modern chemical, corrosion, applied surface science, engineering, and technology [29,30]. Many methods have been used for the functional modification of material surfaces such as self-assembled monolayer formation, functionalized silane, electroplating, layer-by-layer assembly, and hydrothermal crystallization method and genetically engineered surface-binding peptides [29,31-34]. These strategies are aimed at tailoring only the surface properties of the material, to modify its biological activity, while preserving the bulk properties of the underlying support $[35,36]$. Du et al. improved hydrophilicity and surface smoothness of commercial UF PVDF membranes by surface coating with a poly(vinyl alcohol)(PVA) aqueous solution followed by solid-vapour interfacial cross-linking with glutaraldehyde [37]. Electropolymerization is a method of synthesis and deposit of thin layers of polymers on conducting substrates. Many researchers have utilized different monomers and substrates to produce electrochemical conducting, redox, and non-conducting polymer films [38-40].

In this work, chitosan-catechol (CS-CT) synthesised by the Mannich reaction, was electrodeposited onto stainless steel surface and further modified with negatively charged functional groups (maleic anhydride and sulfite) for ameliorating anti-biofouling property. The electro-polymerization was carried out using either cyclic voltammetry or by a constant current or potential electrolysis. Several metal electrodes were used to produce stable polymer films. To further confirm the modification process, the surface elemental composition was characterized via X-ray photoelectron spectroscopy (XPS). Changes of surface hydrophobicity were determined by water contact angle measurements. Further, to investigate the uses of modified chitosan films in biomedical applications, a study of protein adsorption test and antimicrobial test on the modified SS surface was also pursued, the results indicated that the modified SS had lower protein adsorption and improved antibacterial effect. For the aspects of biocompatibility, the study of these modified SS needs to extended. We believe the SS modified by electro-polymerization may boast a great potential and value in biomedical areas in the future.

\section{Materials and methods}

\subsection{Materials}

All chemicals used were of analytical grade and the solutions were prepared with double distilled water. Chitosan (CS, 85\% deacetylation degree, molecular weight $=50,000$ ), paraformaldehyde (PA), catechol (CT), concentrated hydrochloric acid, phosphoric acid, acetone, sodium hydroxide $(\mathrm{NaOH})$, maleic anhydride $(\mathrm{MA})$, sodium sulfite $\left(\mathrm{Na}_{2} \mathrm{SO}_{3}\right)$, standard culturing medium(3.0 g/L beef extract, $5.0 \mathrm{~g} / \mathrm{L} \mathrm{NaCl}, 10.0 \mathrm{~g} / \mathrm{L}$ peptone and $17.5 \mathrm{~g} / \mathrm{L}$ agar), mannitol salt medium(1.0 g/L beef extract, $75.0 \mathrm{~g} / \mathrm{L} \mathrm{NaCl}, 10.0 \mathrm{~g} / \mathrm{L}$ peptone, $10.0 \mathrm{~g} / \mathrm{L}$ $\mathrm{D}$-mannitol, $0.025 \mathrm{~g} / \mathrm{L}$ phenol red and $14.0 \mathrm{~g} / \mathrm{L}$ agar) were purchased from Sinopharm. The commercial 316L stainless steel foil ( $0.2 \mathrm{~mm}$ thick, $10 \mathrm{~mm}$ wide) was ultrasonically cleaned for $20 \mathrm{~min}$ in hexane, acetone, ethanol, $5 \mathrm{wt}$ \% sodium carbonate $\left(\mathrm{Na}_{2} \mathrm{CO}_{3}\right)$ solution and 
pure water in turn and dried by nitrogen at ambient temperature. Pure water was prepared by a pure water system (GWA-UN, PGENERAL, China).

\subsection{Preparation}

\subsubsection{Synthesis of Chitosan-catechol (CS-CT)}

The reactants (2.42 g CS, $0.23 \mathrm{~g}$ PA and $1.65 \mathrm{~g} \mathrm{CT}$ ) and $0.1 \mathrm{M}$ hydrochloric acid solution $(25 \mathrm{~mL})$ were mixed into a $50 \mathrm{~mL}$ round-bottomed flask with a magnetic bar. The sealed flask was then heated to $60{ }^{\circ} \mathrm{C}$ for $12 \mathrm{~h}$ with Mannich reaction. After $200 \mathrm{ml}$ ethanol was dripped slowly into the cooling solution, the white solid precipitate was collected by filtration and freeze-dried for $24 \mathrm{~h}$. Chitosan-catechol (CS-CT) was obtained as shown in step 1 of Scheme 1 .

\subsubsection{Electroplating}

The pristine SS sample was pre-treated with chemical polishing using $70 \%$ phosphoric acid solution and cut into $1 \mathrm{~cm}^{2}$ piece was used as a work electrode in the electrolyte solution (1 wt. \% CS-CT, $50 \mathrm{ml} 0.1 \mathrm{M} \mathrm{NaOH}$ as conducting medium, at $37^{\circ} \mathrm{C}$ ) [41]. Pt ( $1 \mathrm{~mm}$ diameter, $10 \mathrm{~mm}$ length) wire and $\mathrm{Ag} / \mathrm{AgCl}$ (in saturated $\mathrm{KCl}$ ) electrode were used as a counter and a reference electrode respectively. With the above three electrode system, the electrodeposition was executed by an electrochemical workstation ( $\mathrm{CH}$ Instruments $\mathrm{CHI} 660 \mathrm{E})$ and the schematic of electrodeposition is showed in Scheme 2. Then the sample was rinsed by pure water and dried under nitrogen in ambient temperature after being removed from electrochemical cell. The prepared SS sample electrodepositing with chitosan derivatives film, namely SS-CS, was obtained as shown in step 2 of Scheme 1.

\subsubsection{Synthesis of sulfonated chitosan derivatives (SS-CS-MA-S)}

In order to improving the biocompatibility especially anticoagulant property of stainless steel, the prepared SS-CS sample was immersed in an acetone solution containing 0.1 M MA at $40{ }^{\circ} \mathrm{C}$ for $2 \mathrm{~h}$, then rinsed with $25 \%$ aqueous acetone solution to eliminate any possible residual MA, and finally dried by nitrogen at ambient temperature [42]. Immediately, the prepared SS-CS-MA sample was immersed in $0.1 \mathrm{M}$ sodium sulfite solution at ambient temperature for 1 hour and rinsed with pure water and dried by nitrogen gas to acquire the prepared SS-CS-MA-S sample as illustrated in steps 3 and 4 of Scheme 1.

\section{Characterization}

\subsection{The Fourier transform infrared (FT-IR) spectra}

The FTIR spectrum of CS and CS-CT was obtained by KBr pellet pressing method. The FTIR spectrum of modified SS sample was measured on a Nicolet Avatar 370 FTIR (USA) with attenuated total reflectance (ATR) mode. 32 scans at a resolution of $4 \mathrm{~cm}^{-1}$ were averaged and referenced against the air. 


\subsection{The ultraviolet-visible (UV) spectra}

Seven different concentrations of catechol solutions were measured at $275 \mathrm{~nm}$ by ultraviolet-visible spectrophotometer (Agilent 8453, USA) at ambient temperature. The fitted equation between concentration and absorbance was below:

$$
Y=0.0408+0.02058 X\left(R^{2}=0.99925\right)
$$

where $X$ is the concentrations of catechol solution, $Y$ is the absorbance at $275 \mathrm{~nm}$.

\subsection{X-ray photoelectron spectroscopy}

All SS sample's composition of the surface functionalized substrates was measured by a KRATOS Analytical Ultra XPS apparatus with Mg Ka source operating at $12 \mathrm{KV}, 11 \mathrm{~mA}$, and $2 \times 10^{-8}$ Torr. The spectra were calibrated and referenced to $\mathrm{C}$ for $1 \mathrm{~s}$ at $248.6 \mathrm{eV}$.

\subsection{Surface morphologies (SEM and AFM)}

To detect the change in surface topography after surface modification, the surface morphologies of all spraying platinum SS samples were observed by a scanning electron microscope (SEM) (Nova NanoSEM 630, FEI) and an atomic force microscopy (5500 AFM/ SPM, Agilent). The membrane samples were coated with platinum powder according to the standard procedures prior to the scan analysis, and as for AFM, imaging was performed in tapping mode under ambient conditions.

\subsection{Water contact angle measurement}

The hydrophobicity/hydrophilicity of a membrane surface is often indicated by its water contact angle. The hydrophilicity of the all modified SS surface was surveyed by an optical contact angle measuring device (Dataphysics OCA15EC), at $37^{\circ} \mathrm{C}$, relative humidity $35 \%$. The samples were dried in oven at $37^{\circ} \mathrm{C}$ for 3 days before water contact angle analysis. The value of the water contact angle was the average number determined using three samples and four times for each sample in different areas.

\subsection{Electrochemical characterizations}

\subsubsection{Cyclic voltammetry}

The electrochemical experiment was carried out with AUTLAB $302 \mathrm{~N}$ electrochemical workstation (Switzerland) at ambient temperature. The working system was a standard three-electrode cell, the SS sample as the working electrode, the saturated calomel electrode (SCE) as the reference electrode, and the platinum foil as the counter electrode, respectively. The distance between the working electrode $\left(1 \mathrm{~cm}^{2}\right.$ SS sample) and the reference electrode $(\mathrm{Ag} / \mathrm{AgCl})$ was $30 \mathrm{~mm}$, between the work electrode $\left(1 \mathrm{~cm}^{2} \mathrm{SS}\right.$ sample) and the counter electrode (Pt wire) was $20 \mathrm{~mm}$ [43]. The electrochemical behaviors of SS-CS sample were measured by cyclic voltammetry from +0.6 to $+1.1 \mathrm{~V}$ at a scanning rate of $2 \mathrm{mV} \mathrm{s}^{-1}$ and 40 cycles, and $0.1 \mathrm{M} \mathrm{NaOH}$ aqueous solution was set as the supporting electrolyte. 


\subsubsection{Tafel polarization curves}

With the pristine SS sample as control, polarization curves of all the modified SS sample in $50 \mathrm{ml}$ phosphate buffered saline (PBS, $0.01 \mathrm{M}, \mathrm{pH}=7.4$, with 0.8 wt. $\% \mathrm{NaCl}$ ) were investigated in a potential range from -1.0 to $1.4 \mathrm{~V}$ with a scanning rate of $1 \mathrm{mV} \mathrm{s}^{-1}$, at $37^{\circ} \mathrm{C}$.

\subsubsection{Electrochemical impedance spectroscopy}

With the pristine SS sample as control, electrochemical impedance spectroscopy (EIS) of all the modified SS sample in $50 \mathrm{ml}$ phosphate buffered saline (PBS, $0.01 \mathrm{M}, \mathrm{pH}=7.4$, with 0.8 wt. $\% \mathrm{NaCl}$ ) was assayed with the frequency range from $100 \mathrm{kHz}$ to $0.01 \mathrm{~Hz}$ at the open circuit potential and $37^{\circ} \mathrm{C}$.

\subsection{Protein adsorption test}

Protein adsorption is the first event that occurs when a material comes into contact with blood material [44]. Protein adsorption experiments were carried out with Bovine serum albumin (BSA, biotech grade, Biosharp) under the static condition. BSA was chosen because it is chemically similar to human serum albumin (HSA) and also has the highest concentration in blood plasma. BSA adsorption on the surface of the modified SS sample was detected by an electrochemical quartz crystal microbalance (EQCM, Chenhua CHI400C, China). Firstly, the membrane with an area of $0.5 \mathrm{~cm} \times 0.5 \mathrm{~cm}$ was immersed in a phosphate buffer solution (PBS) with $1 \mathrm{mg} \mathrm{ml}^{-1} \mathrm{BSA}$, then the $0.25 \mathrm{~cm}^{2}$ SS sample was stabilized on the surface of quartz crystal at $37^{\circ} \mathrm{C}$, the adsorbed protein amount was calculated by EQCM with increasing time. The amount of protein adsorption is carried out by the following formula (2).

$$
\Delta f=\frac{-2 f_{0}^{2}}{A \sqrt{u \rho}} \Delta m
$$

$\Delta f$ is the frequency changes of EQCM, $\Delta m$ represents the quality changes of quartz crystal oscillations, $f_{0}$ is the basic frequency of the crystal resonant frequency $(8 \mathrm{MHz}), A$ is the artz Crystal Oscillator Gold Coating Area in Gold Electrode $\left(0.205 \mathrm{~cm}^{2}\right), u$ is the shear modulus of quartz $\left(2.947 \times 1011 \mathrm{~g} / \mathrm{cm} \mathrm{s}^{2}\right), \rho$ is density of quartz $\left(2.648 \mathrm{~g} / \mathrm{cm}^{3}\right)$. For QCM used in this study, a mass change of $0.14 \mathrm{ng}$ corresponds to a frequency change of $0.1 \mathrm{~Hz}$.

\subsection{Antimicrobial test}

All experiment equipment was sterilized at $121^{\circ} \mathrm{C}$ in an autoclave for $20 \mathrm{~min}$, and the modified $1 \mathrm{~cm}^{2}$ SS samples were sterilized under sterilamp for $30 \mathrm{~min}$. Staphylococcus aureus (S. aureus) and Escherichia coli (E. coli), which represented as Gram-positive and Gram-negative bacteria, respectively, were cultured in the standard culturing solutions. After Sterilization by autoclave at $121^{\circ} \mathrm{C}$ for $20 \mathrm{~min}$, the culturing solutions containing the bacteria were diluted to $5.5 \times 10^{5} \mathrm{cfu} / \mathrm{ml}$ with $0.85 \mathrm{wt}$. $\% \mathrm{NaCl}$ solutions.

The antimicrobial test was carried out by agar plate method with thin-film adhering test $[39,45] .20 \mu$ diluted suspension was absorbed to the surface of SS sample by pipette. Immediately, the modified SS sample was covered by $0.81(0.9 \times 0.9) \mathrm{cm}^{2}$ sterile PE thin films for expanding the diluted suspension and maintained in a sterile culture dish for $24 \mathrm{~h}$ 
at $37^{\circ} \mathrm{C}$, in the relative humidity of over $90 \%$. After that, the covered SS sample was washed by $20 \mathrm{ml} 0.85 \mathrm{wt}$. \% NaCl solution and shook it adequately. $0.5 \mathrm{ml}$ eluent was absorbed in the standard culturing medium for E. coli and mannitol salt medium for S. aureus with continuous culture for $48 \mathrm{~h}$ at $37^{\circ} \mathrm{C}$. All experiments were performed for three times. The relative sterilizing rate of the bacteria can be calculated.

\section{Results and discussion}

\subsection{Synthesis of chitosan derivatives}

\subsubsection{FTIR spectra analysis}

The structure changes of chitosan and the derivatives of chitosan were confirmed by FTIR. As shown in Figure 1, compared to the IR spectrum of chitosan, the spectra of CS-CT showed new peaks at 1625 and $750 \mathrm{~cm}^{-1}$. The intense and broad absorption bands for CS-CT sample observed at $1625 \mathrm{~cm}^{-1}$ can be attributed to the stretching vibration of amide groups $(\mathrm{C}=\mathrm{O}-\mathrm{NHR})$ while the absorption at the same position for the CS may be due to the incomplete degree of deacetylation. In addition, the ortho-disubstituted benzene bond at $750 \mathrm{~cm}^{-1}$ formed the initial evidence of the truth that the catechol had grafted onto the chitosan polymer chain [46], which indicated that the Chitosan-catechol was synthesised.

However, according to Figure 2, the absorption for SS-CS at 1630, 1060, and $750 \mathrm{~cm}^{-1}$ were due to stretching vibration of the amide bond, glycosidic bond and ortho-disubstituted benzene bond, respectively. It indicated that CS-CT sample had been electrodeposited on the surface of SS successfully. The most characteristic absorption at $1715 \mathrm{~cm}^{-1}$ of SS-CS-MA responded to $\mathrm{C}=\mathrm{O}$ stretching vibration of carboxyl groups, which could prove the introduction of carboxyl groups into SS-CS [47]. The presence of the band at $808 \mathrm{~cm}^{-1}$ from C-O-S vibration and $1222 \mathrm{~cm}^{-1}$ from $\mathrm{S}=\mathrm{O}$ vibration of SS-CS-MA-S confirmed the introduction of sulfonic acid groups into SS-CS-MA [40].

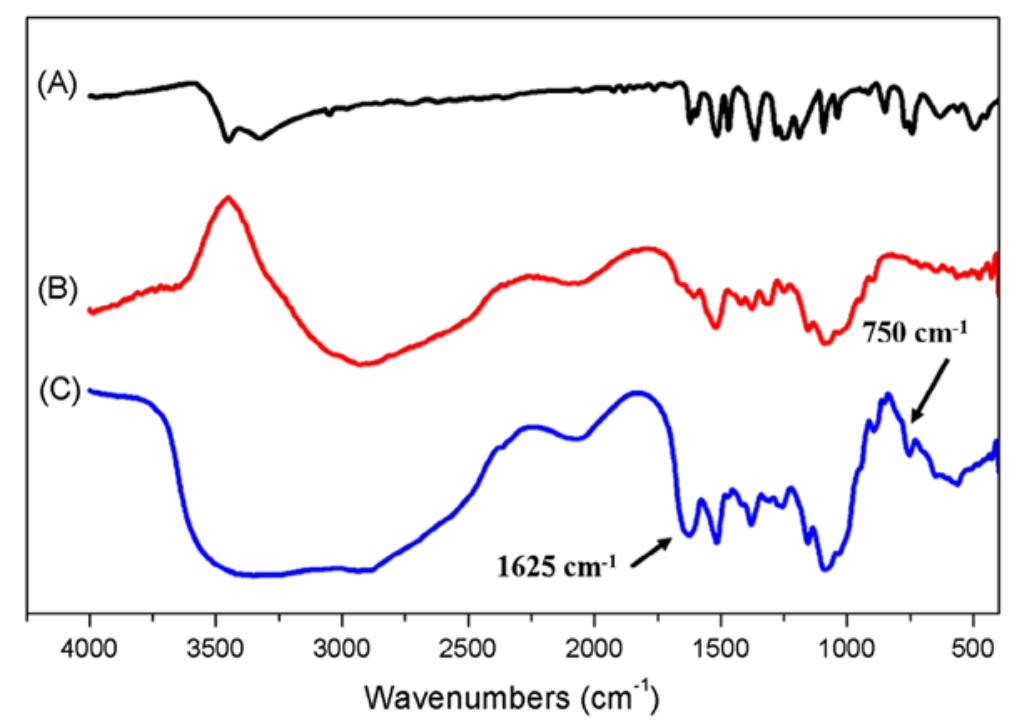

Figure 1. FTIR Spectra of (A) catechol, (B) chitosan and (C) Chitosan derivatives CS- CT. 


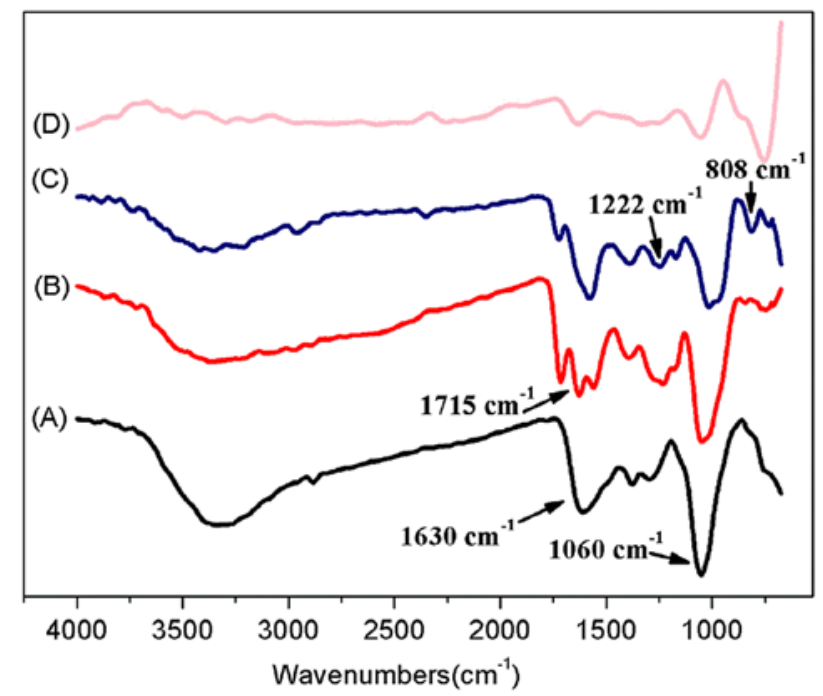

Figure 2. ATR-FTIR Spectra of (A) SS-CS, (B) SS-CS-MA(SS-CS treated by MA for $2 \mathrm{~h}$ ), (C) SS-CS-MA-S and (D) SS.

In addition, these results also suggest that the modified layer on the SS is thick enough to be detected by the ATR-FTIR technique with a sampling depth of about $1-2 \mu \mathrm{m}$.

\subsubsection{UV spectrophotometer analysis}

Figure 3 reveals that the characteristic absorption peak at about $275 \mathrm{~nm}$ of CT and CS-CT sample while the absence of this absorption peak of CS. It further suggested the catechol had been grafted onto the chitosan polymer chain. The absorbance of CS-CT solution could be measured at $275 \mathrm{~nm}$, the concentration of CT was calculated according to formula (1)

The catechol's grafting ratio was estimated according to formula (3).

$$
W \%=M_{1} / M_{2} \times 100 \%=C_{1} / C_{2} \times 100 \%
$$

where $M_{1}$ and $C_{1}$ is mass and concentration of CT, respectively; $M_{2}$ and $C_{2}$ is mass and concentration of CS-CT sample, respectively. The grafting ratio was about $15.59 \%$.

\subsubsection{XPS spectra analysis}

In order to analyze of surface chemical properties, the further characterization on the surface of pristine SS and modified SS samples were assayed by XPS spectra. As is shown in Table 1 , the carbon and nitrogen composition of modified SS sample was significantly larger than the pristine SS, which could be ascribed that the organic thin film of chitosan derivatives on the modified SS [48]. However, the high composition of oxygen in pristine SS may be attributed to the metal oxides on the surface of pristine SS. The high resolution spectra can provide more information about the type of the chemical bonds. As is displayed in Table S1 and corresponding high resolution spectra from Figure 4, XPS analyses clearly demonstrated the efficiency of the carboxylation and sulfonation process on chitosan. Three decomposed peaks at 284.8, 286.5 and $288.2 \mathrm{eV}$ in the high-resolution XPS spectra in the C 1 s of SS-CS sample was corresponded to C-H/ C-C, C-O/C-N and CO-NH, respectively [42]. The peak 


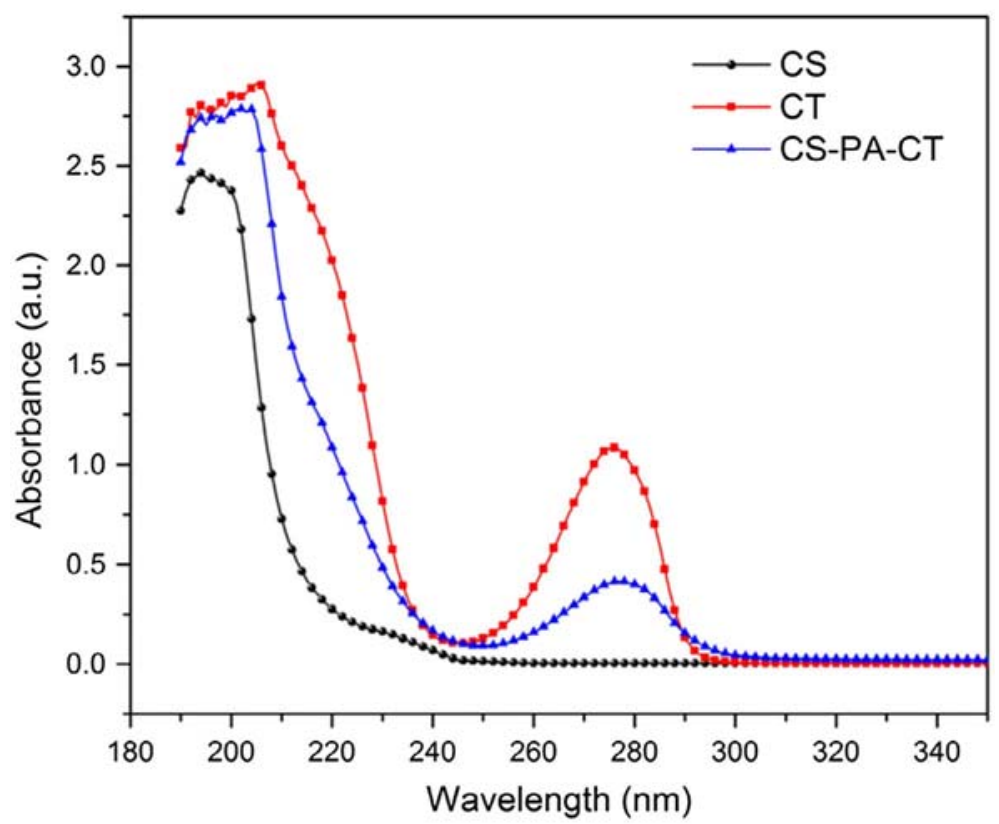

Figure 3. UV spectrophotometer of chitosan (CS), catechol (CT), Chitosan derivatives (CS-CT).

Table 1. Surface elemental composition on pristine SS and modified SS samples.

\begin{tabular}{|c|c|c|c|c|c|c|c|c|c|c|c|c|}
\hline \multirow[b]{2}{*}{ Sample type } & \multicolumn{12}{|c|}{ Percent of atomic composition (\%) } \\
\hline & $C$ & $N$ & 0 & $S$ & $P$ & $\mathrm{Si}$ & $\mathrm{Ni}$ & Mo & $\mathrm{Cr}$ & $\mathrm{Mn}$ & Co & $\mathrm{Fe}$ \\
\hline Pristine SS & 39.15 & 0.83 & 29.60 & 2.28 & 0.26 & 25.73 & 0.32 & 0.06 & 0.31 & 0.14 & 0.14 & 1.21 \\
\hline SS-CS & 67.66 & 3.03 & 23.79 & - & 0.01 & 5.30 & 0.10 & 0.04 & - & 0.07 & - & - \\
\hline SS-CS-MA & 67.08 & 3.20 & 23.33 & - & - & 6.37 & 0.02 & 0.01 & - & - & - & - \\
\hline SS-CS-MA-S & 57.02 & 3.90 & 30.22 & 5.94 & - & 2.14 & 0.15 & 0.40 & 0.24 & - & - & - \\
\hline
\end{tabular}

at $288.2 \mathrm{eV}$ could be attributed to the incomplete deacetylation of chitosan. Nevertheless, the new components at $288.9 \mathrm{eV}$ were discovered in the MA modified SS-CS sample, namely SS-CS-MA and SS-CS-MA-S, which was assigned to the carboxylic acid groups. $5.94 \%$ of sulfur was detected in the SS-CS-MA-S sample whereas no sulfur was existed in the SS-CS sample and SS-CS-MA sample. The two divided components in high-resolution XPS spectra in the S 2p of SS-CS-MA-S sample could be attributed to sulfonate groups(S 2p3/2 at $167.9 \mathrm{eV}$ ) and sulfate groups(S 2p1/2 at $168.7 \mathrm{eV}$ ) [48]. These data indicated that the SS-CS was further modified by maleic anhydride and sulfite.

In short, all of the results above demonstrate that the target sulfonated chitosan derivatives have been synthesised and coated onto the surface of 316L stainless steel successfully.

\subsection{Corrosion resistance of SS surface before and after modification}

\subsubsection{Cyclic voltammetry analysis}

Cyclic voltammetry has been employed to investigate the behaviour of 316L stainless steel electrodes in $0.1 \mathrm{M} \mathrm{NaOH}$ aqueous solutions supporting electrolyte. The effect of the CS-CT 
(A)

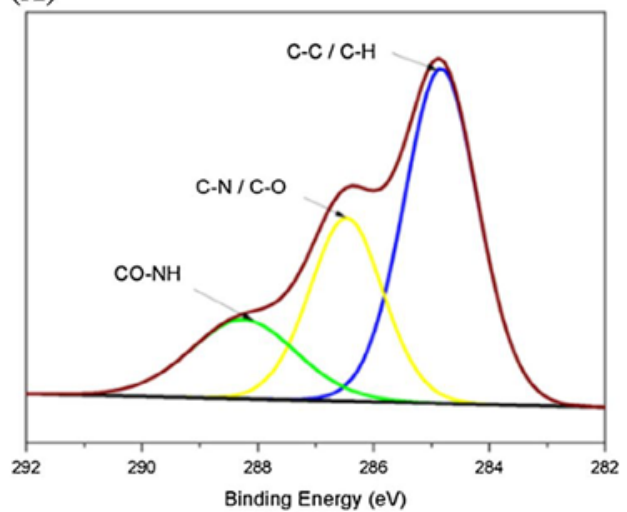

(C)

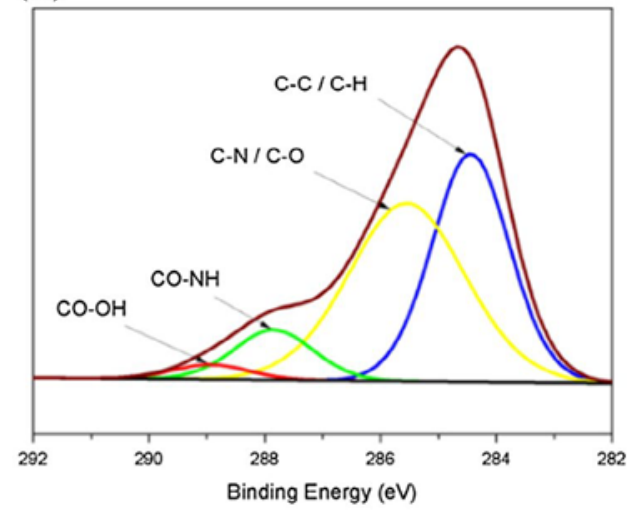

(B)

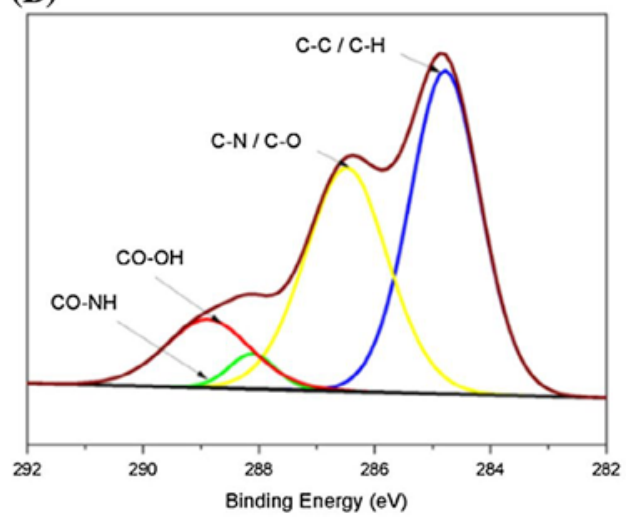

(D)

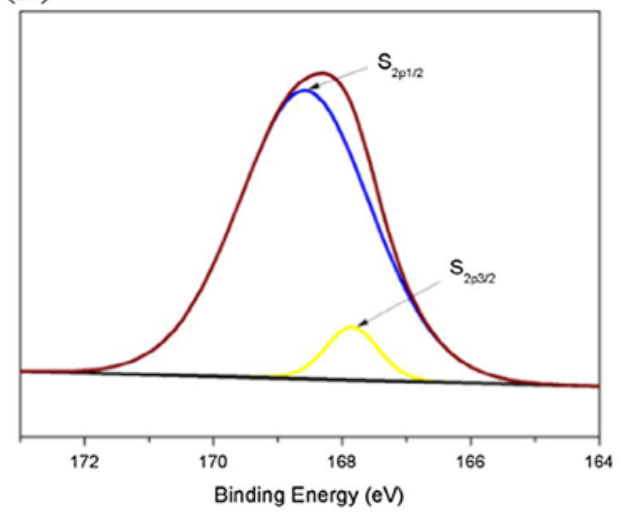

Figure 4. The high resolution spectra with C 1s of (A) SS-CS, (B) SS-CS-MA(SS-CS treated by MA for $2 \mathrm{~h}$ ), (C) SS-CS-MA-S and S 2p of (D) SS-CS-MA-S.

concentration is shown in Figure S1. Below the concentration of $1 \mathrm{mg} \mathrm{mL}^{-1}$, there were no obvious oxidation peaks, which indicated few irreversible oxidation reaction occurred on the electrode surface, while upon $1 \mathrm{mg} \mathrm{mL}^{-1}$, the oxidation potential decreased with increasing the concentration of CS-CT, it was attributed to the larger resistance caused by the high concentration in the solution. The cyclic voltammetry curves of SS-CS sample in different cycles were illustrated by Figure 5. There was a broad anodic peak at potential around $+0.97 \mathrm{~V}$, which indicated catechol's oxidation polymerization on stainless steel surface. It could attribute to the two electron-donating hydroxyl groups $(-\mathrm{OH})$ on benzene. The current intensity gradually reduced with increasing scanning, which is due to the gradual thickening of an insulating film deposited with irreversible oxidation polymerization of CS-CT.

\subsubsection{Tafel polarization curves analysis}

The Tafel polarization curves of all modified SS samples in PBS solution were shown in Figure 6. It is obvious that the corrosion potential of SS-CS, SS-CS-MA and SS-CS-MA-S samples were enhanced to $-0.343,-0.286$ and $-0.324 \mathrm{~V}$ respectively compared with the truth that corrosion potential of pristine SS sample was $-0.389 \mathrm{~V}$. The elevation of potential 


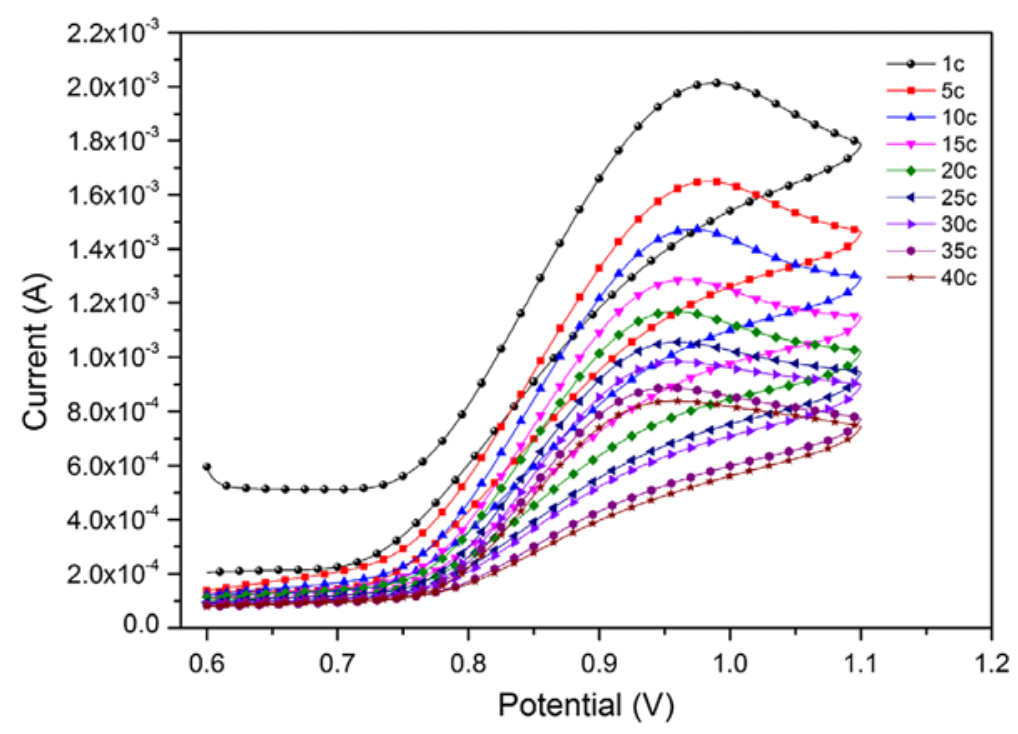

Figure 5. Cyclic voltammetry curves of SS-CS sample with different cycles, pristine SS electrode immersed in $0.1 \mathrm{M} \mathrm{NaOH}$ aqueous solutions containing $2.4 \mathrm{mg} \mathrm{mL}^{-1} \mathrm{CS}-\mathrm{CT}$.

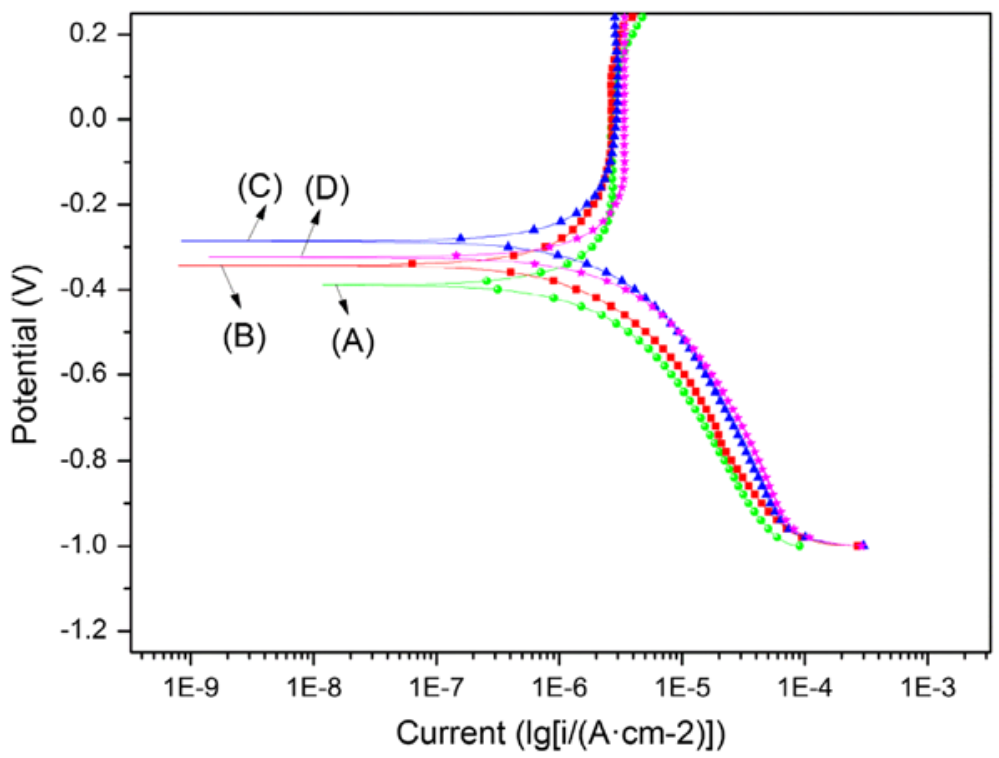

Figure 6. Tafel polarization curves of (A) pristine SS, (B) SS-CS, (C) SS-CS-MA(SS-CS treated by MA for $2 \mathrm{~h}$ ) and (D) SS-CS-MA-S.

corrosion demonstrated that the modification of chitosan derivatives played an essential role in resistance to localized corrosion. 


\subsubsection{EIS analysis}

EIS is a powerful, nondestructive electrochemical technique for the characterization of electrochemical reactions at the metal/film interface. As shown in Figure 7, the impedance spectra surveyed at the open circuit potential for pristine and modified SS samples exposed to PBS at $37^{\circ} \mathrm{C}$. Compared with pristine SS samples, the modified SS samples showed a higher value and a broader phase angle which suggests a higher corrosion resistance than the pristine SS. The aforementioned results indicated that the formation of sulfonated chitosan
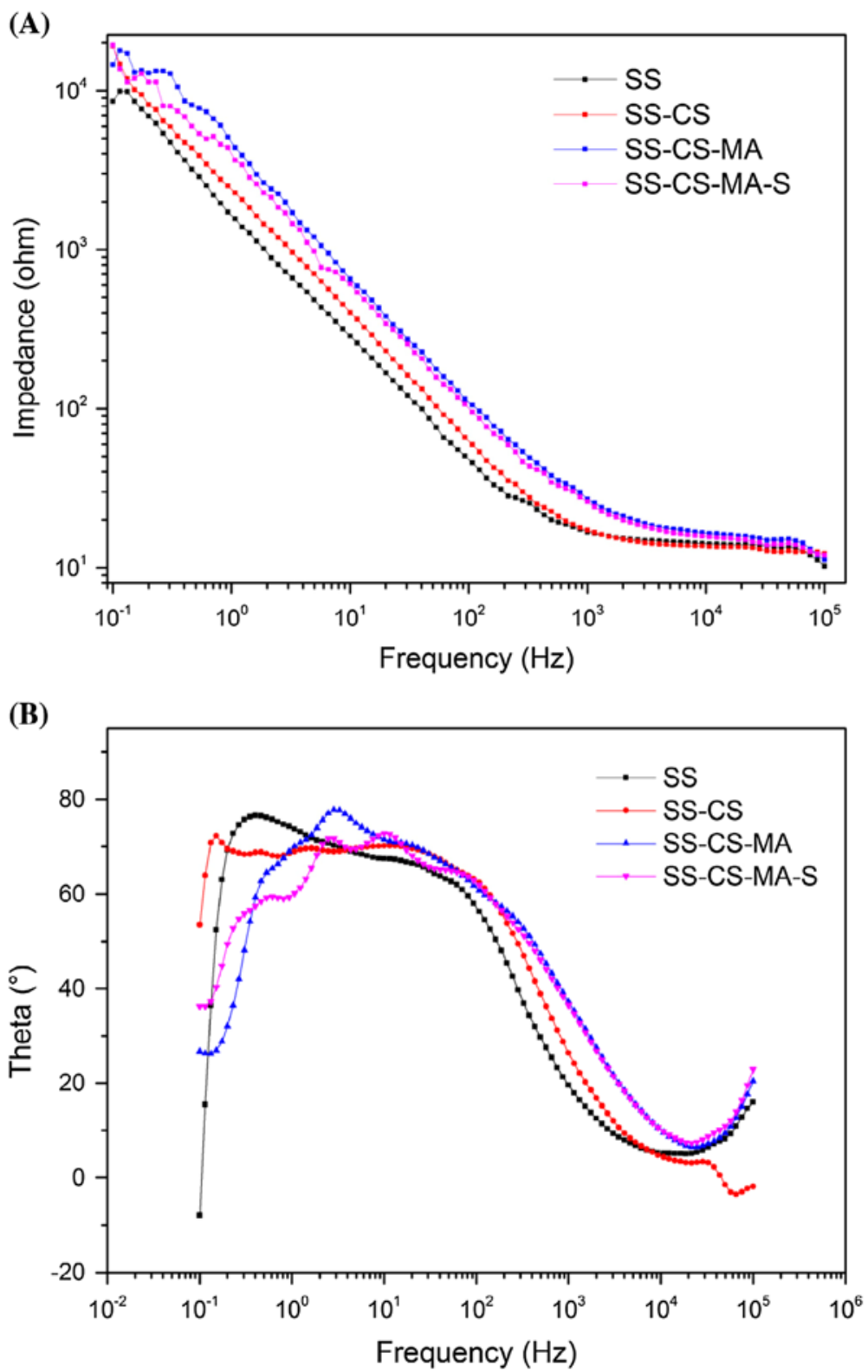

Figure 7. Bode plots of pristine SS, SS-CS, SS-CS-MA (SS-CS treated by MA for $2 \mathrm{~h}$ ) and SS-CS -MA-S. (A) Impedance spectra, (B) Theta spectra. 
derivatives films on the 316L SS surface consequently prevents the SS from corroding. Besides that, we checked the impedance plots according to the equivalent circuit reported by Chen [35], the circuit elements, Nyquist plots and detailed fitted values are shown in Figure S2, Figure S3 and Table S2, respectively. The diameter of the semicircle in Nyquist plots represented the value of the charge-transfer resistance $R_{c t}$ it can be found obviously that the $R_{c t}$ of modified SS was bigger than pristine SS, while the charge-transfer resistance decreased with the progress of modification, it was mainly attributed to the introduction of hydrophilic carboxyl and sulfonic acid groups, which have good electron conductivity properties.

All the results above prove the fact that the modification of chitosan derivatives can act as an additional barrier between SS surface and electrolyte.

\subsection{Surface morphology and hydrophilicity analysis}

The surface morphology of the SS surface was characterized by AFM. Figure 8 shows the AFM 3D micrographs of the boundary area between pristine SS and SS-CS. The surface morphology was significantly different, it is obviously that the roughness of SS-CS area increased more than pristine SS. The thickness of chitosan film observed was about $33 \mathrm{~nm}$. The distinct morphology between smooth pristine SS and rough SS-CS also can be assayed with SEM as shown in Figure 9, suggesting that the introducing CS to pristine SS was successfully. The morphological image of SS-CS showed its porous membrane structure obviously. However, the SS-CS-MA and SS-CS-MA-S samples exhibited more and larger pore structure. It may be attribute to the embedded hydrophilic branched chain (maleic acid and sulfonic acid), leading to the more loose membrane or even formation of $3 \mathrm{D}$ microporous network structure [25]. The water contact angles of SS surface before and after these modifications are also shown in Figure 9. The water contact angles of all modified SS sample were dramatically reduced compared with pristine SS for good hydrophilic hydroxyl group of CS. As is shown in Figure 10, with increasing time of SS-CS sample treated by MA, the water contact angle of SS-CS-MA sample gradually decreased from $64^{\circ}$ to $50^{\circ}$, which is attributed to the amount of increasingly grafting carboxyl hydrophilic groups of MA, similar results were found from the work of Wei Zhang [42]. Simultaneously, the

(A)

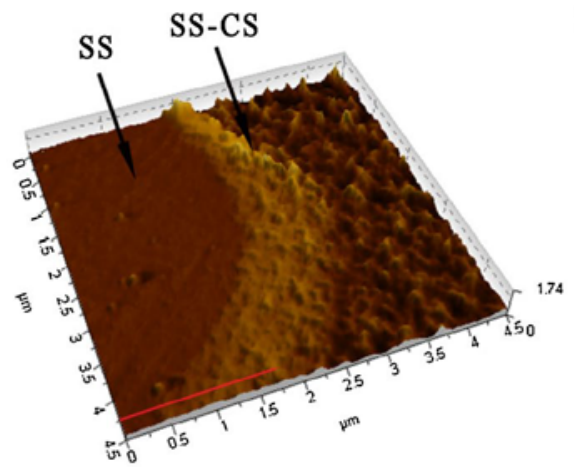

(B)

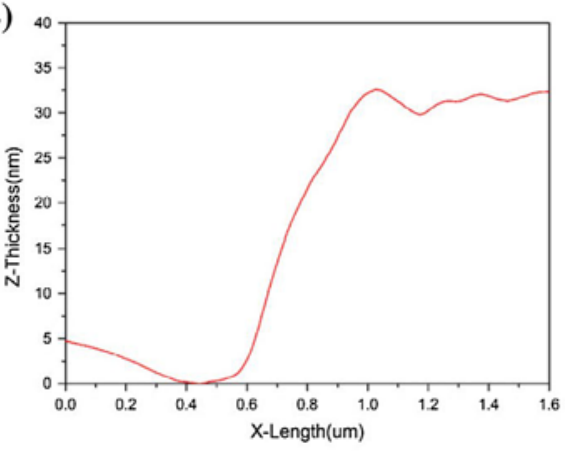

Figure 8. AFM micrographs of the boundary area between SS and SS-CS. (A) 3D AFM micrographs. (B) Surface profiles along the line depicted in Figure 8(A). 


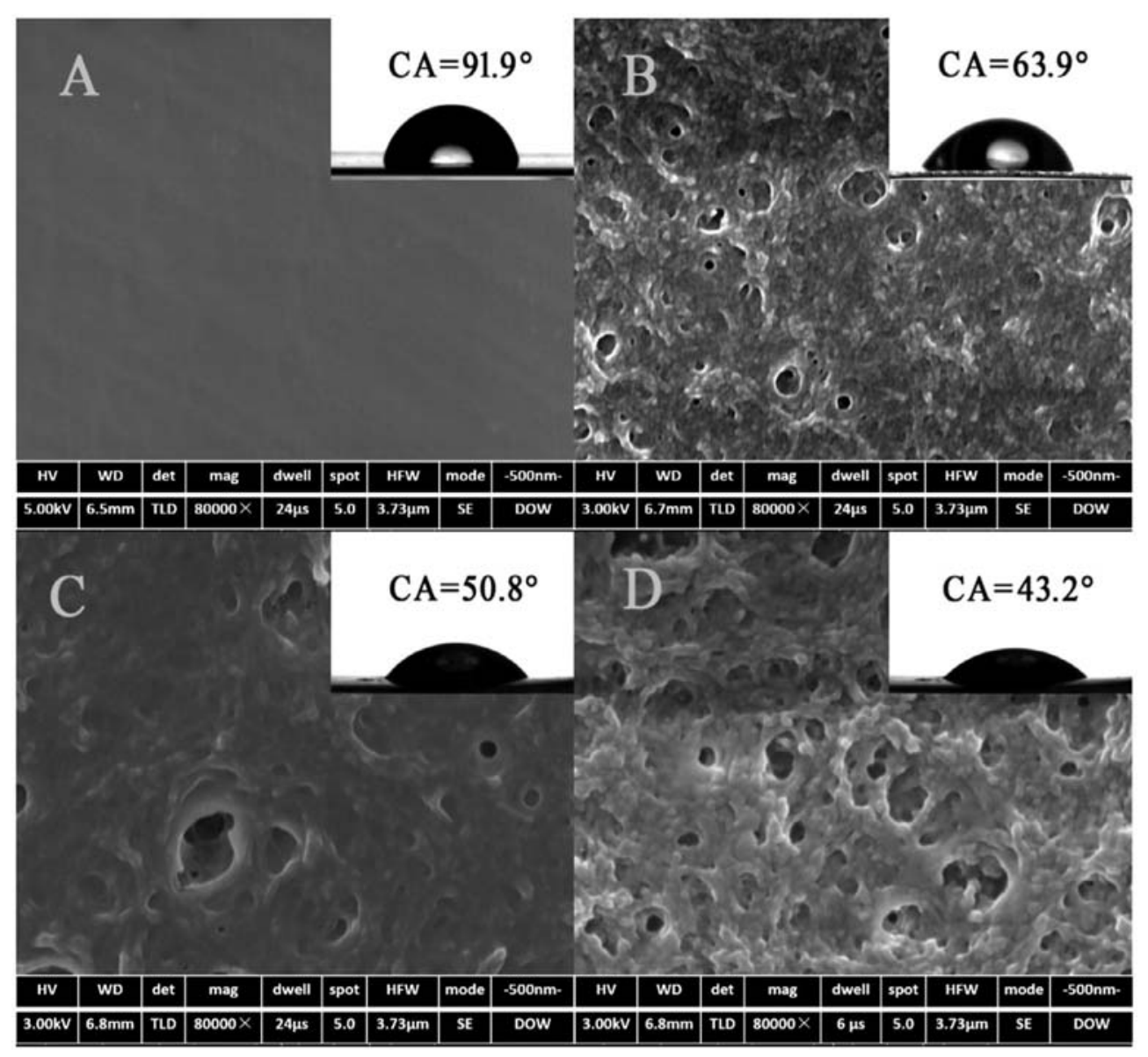

Figure 9. SEM micrographs of (A) pristine SS, (B) SS-CS, (C) SS-CS-MA(SS-CS treated by MA for $2 \mathrm{~h}$ ) and (D) SS-CS-MA-S.

water contact angle of SS-CS-MA-S sample became smaller than SS-CS-MA, it is due to the introduction of sulfonic acid hydrophilic groups by SS-CS-MA-S sample. The water contact angle variations with different treatment steps reflected the change of surface component. In short, the hydrophilicity of the modified SS has been effectively improved.

\subsection{Protein adsorption analysis}

Protein adsorption was one of the well-recognized important factors to evaluate the blood compatibility of materials. As shown in Figure 11, there is no surprise that the BSA adsorbed amount increased over time, and then became steady. It was found that the BSA adsorbed amount of all modified SS samples was less compared to that of the pristine SS. With the progress of the modified reaction on the SS, the BSA adsorbed amount became less, which may be attributed to two possible reasons: On one hand, the hydrophilic chitosan derivatives can prevent BSA from adsorbing and adhering to SS, Zhang and his coworkers explained that the molecular units of the hydrophilic surface have the ability to tightly bind structure 


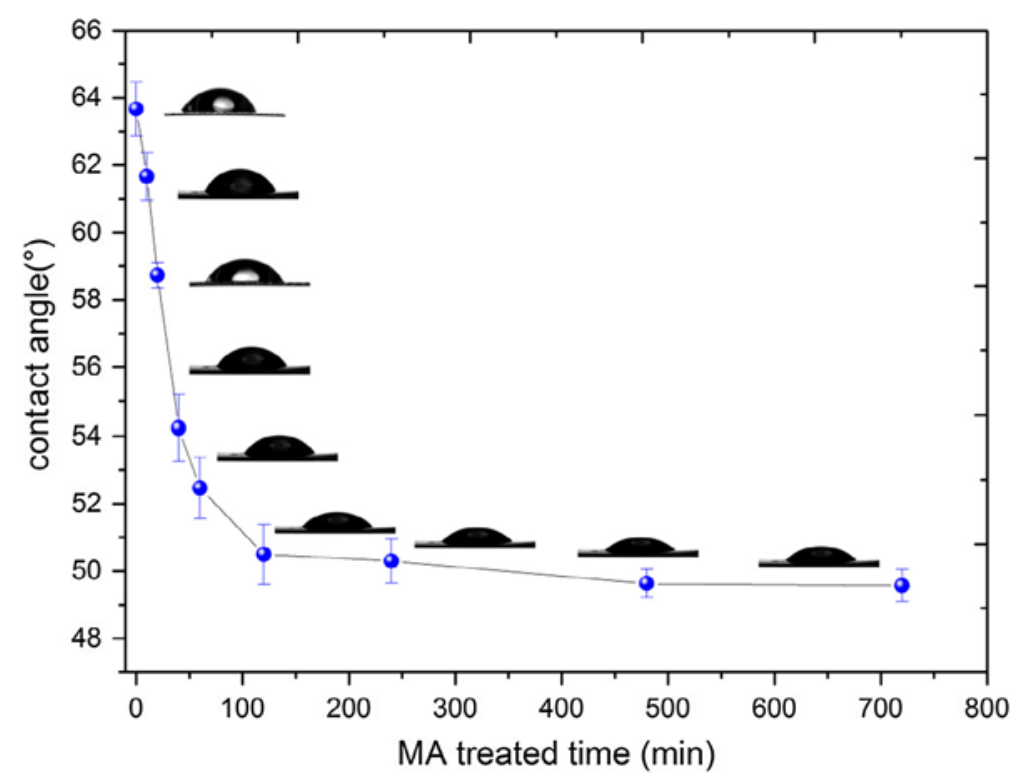

Figure 10. Water contact angles on the surface of the SS-CS sample as a function with the MA treated time.

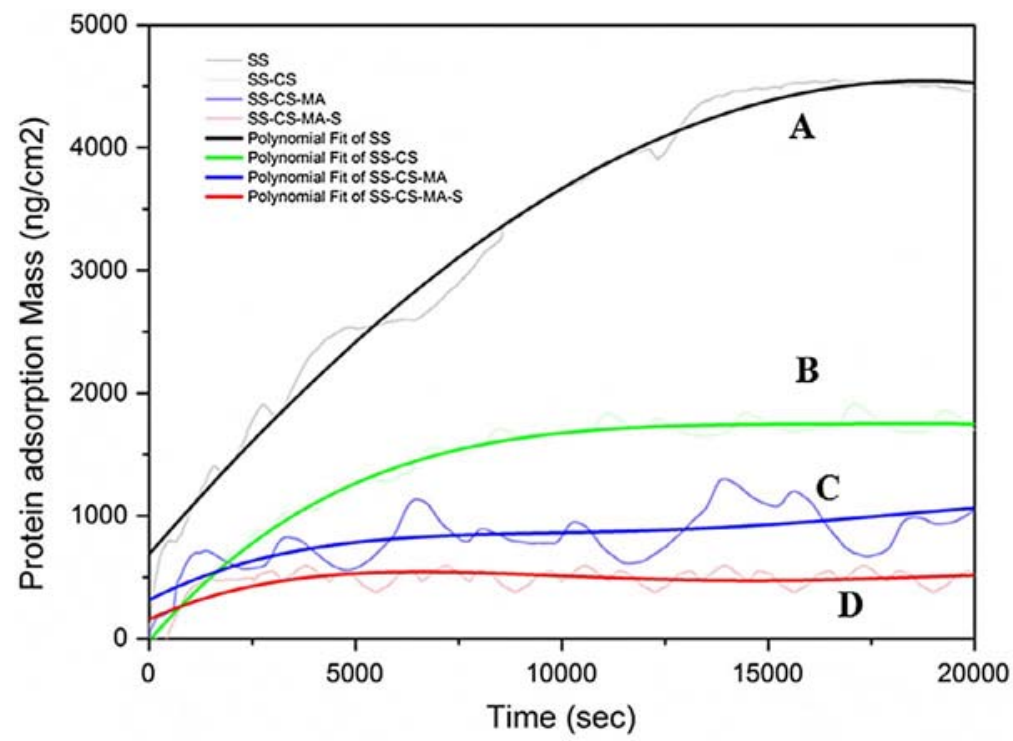

Figure 11. Protein adsorption of (A) pristine SS, (B) SS-CS, (C) SS-CS-MA(SS-CS treated by MA for $2 \mathrm{~h}$ ) and (D) SS-CS-MA-S.

water, and then the tightly bound surface water may cause the low protein adsorption at low protein solution concentrations [49]. On the other hand, chitosan modifying with negatively charged functional groups, namely carboxyl from maleic anhydride and sulfonic acid from sodium sulfite, aims to be less prone to bio-adhesion than positively charged chitosan surface because of the electrostatic repulsion, for many bacteria with solutions 
usually exhibit negative electrical charges [50]. Since the protein adsorption has become one of the key factors in biofouling of medical metal surfaces [51], the superior anti-adsorption protein performance of modified SS material was likely to become the highlight of novel anti-biofouling material.

\subsection{Antimicrobial analysis}

Figure 12 shows the micrographs of $S$. aureus and E. coli on the agar plates for the tested samples. Through counting the bacterial colony number of each antibacterial test, the average antibacterial rate against $S$. aureus and $E$. coli can be calculated. The antimicrobial effect was evaluated by the agar plate method which was used to culture and count live bacteria. Correspondingly, the relative sterilizing rates against both E. coli and S. aureus for modified SS samples are listed in Table 2. All experiments were performed with three replications and the relative sterilizing rate of the bacteria was calculated according to formula (3).

$$
R=(C-A) / C \times 100 \%
$$

where $R$ was the relative sterilizing rate, $C$ was the mean number of bacteria on the control sample (pristine SS) and A was the mean number of bacteria on the analyzed sample (modified SS).

As Figure 12 and Table 2 shown, it can be seen that the SS-CS samples showed excellent antimicrobial capabilities against both E. coli and S. aureus. However, the antimicrobial effectiveness against $E$. coli and $S$. aureus was reduced after introduction of carboxyl groups and sulfonic acid groups. It may be due to the samples' being oppositely affected by the surface characteristics of biomaterial between adhesion and growth of bacterial [52]. The positively charged chitosan surfaces may attract more bacterial for electrostatic attraction, but this effect is readily counterbalanced by the absence of any growth. Therefore, positively charged surfaces may own good antimicrobial properties. On the contrary, the negatively

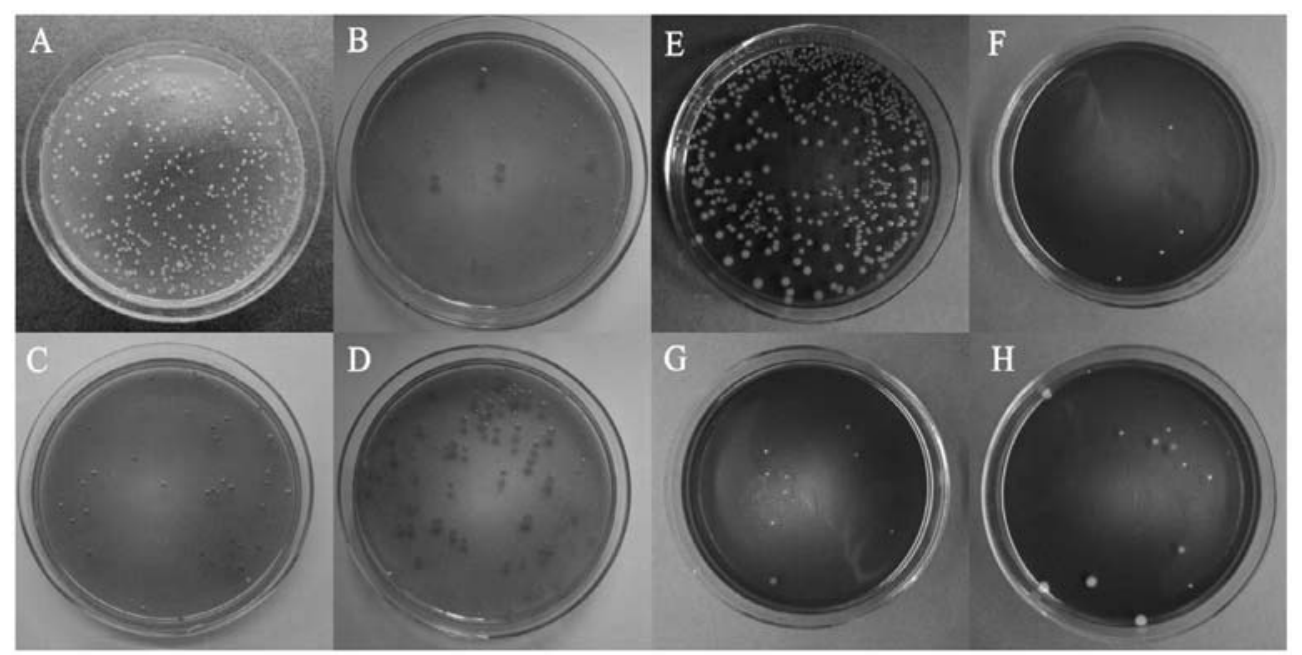

Figure 12. Antimicrobial Effect against E. coli of (A) pristine SS, (B) SS-CS, (C) SS-CS-MA(SS-CS treated by MA for $2 \mathrm{~h}$ ) and (D) SS-CS-MA-S; antimicrobial Effect against S. aureus of (E) pristine SS, (F) SS-CS, (G) SSCS-MA(SS-CS treated by MA for $2 \mathrm{~h}$ ) and (H) SS-CS-MA-S. 

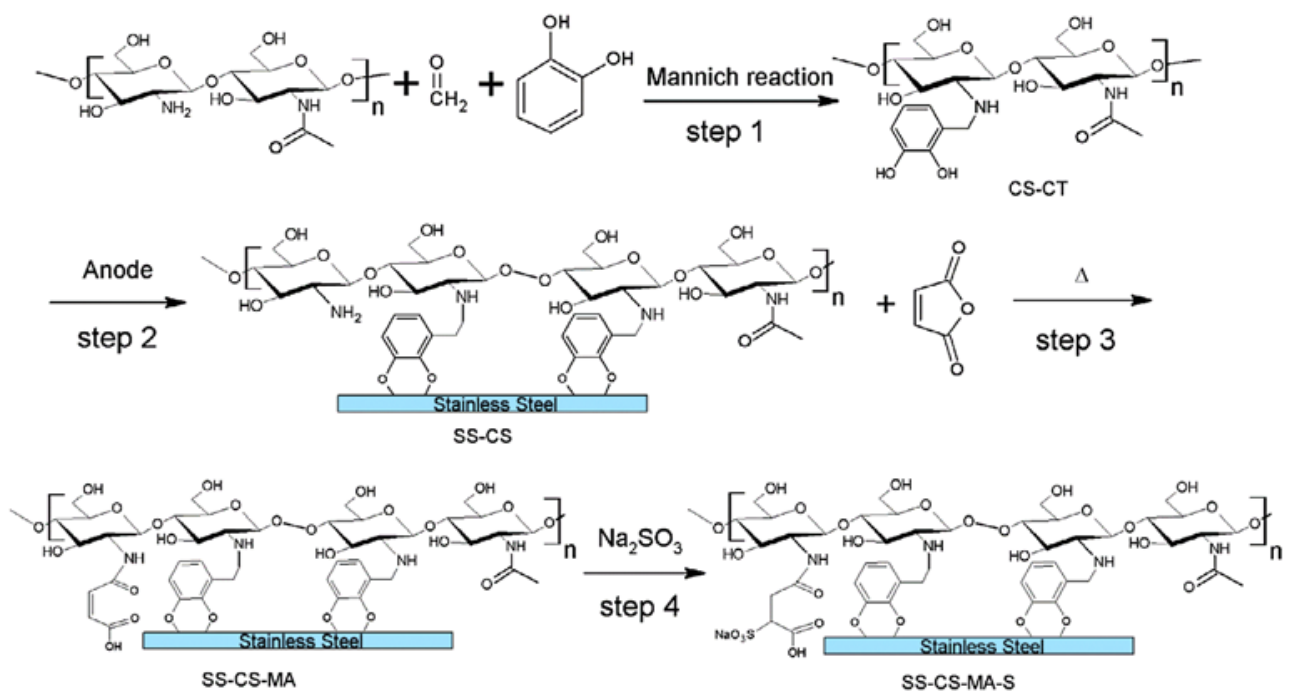

Scheme 1. Procedure of modified stainless steel.

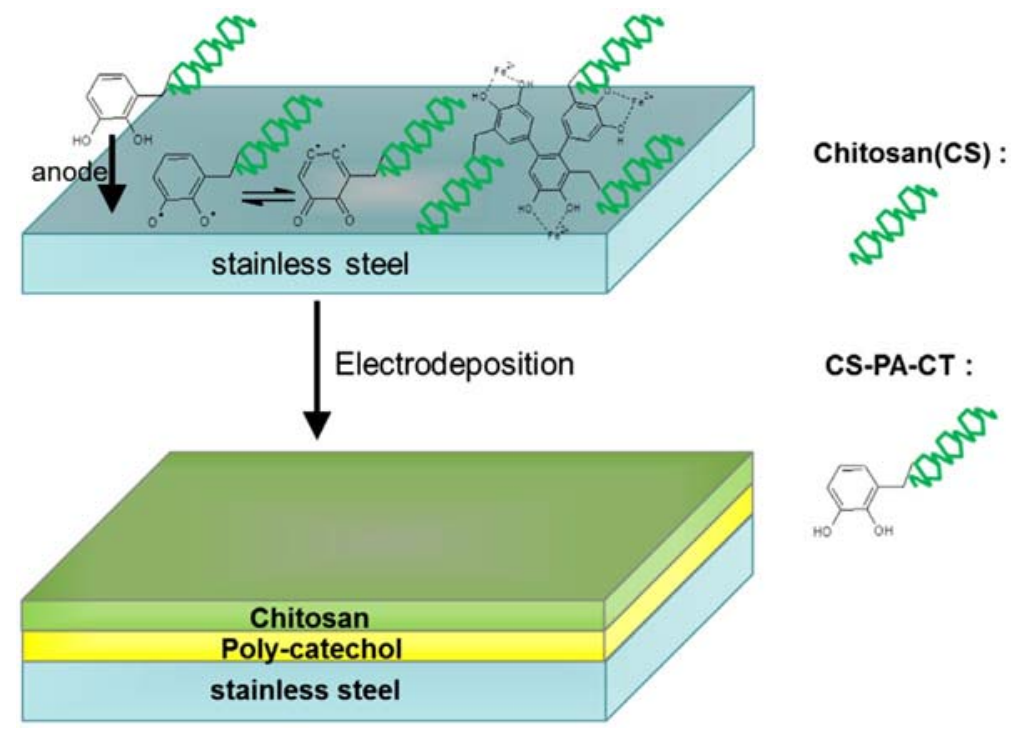

Scheme 2. Electrodeposition of chitosan depending on catechol.

Table 2. Average sterilization rate against E. coli and S. aureus.

\begin{tabular}{lcc}
\hline Sample type & Average sterilization rate against $E$. coli (\%) & Average sterilization rate against S. aureus (\%) \\
\hline Pristine SS & - & - \\
SS-CS & 88.12 & 98.89 \\
SS-CS-MA & 86.86 & 97.69 \\
SS-CS-MA-S & 68.21 & 95.66 \\
\hline
\end{tabular}


charged modified chitosan surfaces may not attract more bacterial for electrostatic repulsion, but the effect lead to desorption of bacterial and unable to prevent the growth of bacteria $[9,39]$. The antimicrobial efficacy against $S$. aureus was higher than E. coli may be ascribed to the different structure of the cytoplasmic membrane [53]. It could conclude that the antimicrobial efficacy of modified SS samples against E. coli and S. aureus was improved significantly compared with pristine SS.

\section{Conclusions}

A new sulfated derivative of chitosan was successfully deposited onto stainless steel surface by an electrochemical method. FTIR spectra and high-resolution carbon XPS spectrum of the SS surface with a derivative of chitosan confirmed the successful coating onto the SS surface. The morphology of the SS surface characterized by atomic force microscopy (AFM), SEM was significantly altered after modifying, and the thickness of the film on the SS-CS was approximately $33 \mathrm{~nm}$. The decreasing water contact angle proves the hydrophilicity of the modified SS has been effectively improved. The corrosion behavior of the films was evaluated by Tafel polarization curve and EIS. The results indicate that the electrodepositing of biocompatible chitosan derivatives ameliorates the ability in resistance against localized corrosion. Protein adsorption and antimicrobial test demonstrated that the modified SS has lower protein adsorption and stronger antibacterial properties. Based on our experiment results, the electrodeposition is supposed to possess a large potential value as a convenient and promising method to ameliorate the surface properties of stainless steel in biomedical application field. In order to better understand the properties of modified SS, more specialized biological experiments need to be done in the future study. This study provides some implication in the modified research of 316L stainless steel.

\section{Acknowledgements}

The authors thank Analysis and Testing Centre of Shanghai University, Dr. Hui Wang, Shanghai Advanced Research Institute and Chinese Academy of Sciences for their advice and assistance with this work and for the use of their corresponding research facilities.

\section{Disclosure statement}

No potential conflict of interest was reported by the authors.

\section{References}

[1] Niinomi M. Recent metallic materials for biomedical applications. Metall Mater Trans A. 2002;33(3):477-486. DOI:10.1007/s11661-002-0109-2.

[2] Guo W, Zhu J, Cheng Z, et al. Anticoagulant surface of $316 \mathrm{~L}$ stainless steel modified by surfaceinitiated atom transfer radical polymerization. ACS Appl Mater Interfaces. 2011 May;3(5):16751680. DOI:10.1021/am200215x. PubMed PMID: 21528878.

[3] Shih C-C, Shih C-M, Su Y-Y, et al. Effect of surface oxide properties on corrosion resistance of 316L stainless steel for biomedical applications. Corros Sci. 2004;46(2):427-441. DOI:10.1016/ s0010-938x(03)00148-3 
[4] Shi X, Yang Z, Nguyen TA, et al. An electrochemical and microstructural characterization of steel-mortar admixed with corrosion inhibitors. Sci China Ser E: Technol Sci. 2009;52(1):52-66. DOI:10.1007/s11431-008-0276-5

[5] Yuan S, Pehkonen S, Ting Y, et al. Inorganic- organic hybrid coatings on stainless steel by layerby-layer deposition and surface-initiated atom-transfer-radical polymerization for combating biocorrosion. ACS Appl Mater Interfaces. 2009;1(3):640-652.

[6] Da Silva S, Basséguy R, Bergel A. Electron transfer between hydrogenase and 316L stainless steel: identification of a hydrogenase-catalyzed cathodic reaction in anaerobic mic. J Electroanal Chem. 2004;561:93-102. DOI:10.1016/j.jelechem.2003.07.005

[7] Shustak G, Domb AJ, Mandler D. Preparation and characterization of n -alkanoic acid selfassembled monolayers adsorbed on 316L stainless steel. Langmuir. 2004;20(18):7499-7506.

[8] Yuan S, Pehkonen S, Ting Y, et al. Antibacterial inorganic- organic hybrid coatings on stainless steel via consecutive surface-initiated atom transfer radical polymerization for biocorrosion prevention. Langmuir. 2009;26(9):6728-6736.

[9] Liu CX, Zhang DR, He Y, et al. Modification of membrane surface for anti-biofouling performance: effect of anti-adhesion and anti-bacteria approaches. J Membr Sci. 2010;346(1):121-130. DOI:10.1016/j.memsci.2009.09.028

[10] Huang L-Y, Yang M-C. Hemocompatibility of layer-by-layer hyaluronic acid/heparin nanostructure coating on stainless steel for cardiovascular stents and its use for drug delivery. J Nanosci Nanotechnol. 2006;6(9):3163-3170. DOI:10.1166/jnn.2006.430

[11] Yuan Y, Ai F, Zang X, et al. Polyurethane vascular catheter surface grafted with zwitterionic sulfobetaine monomer activated by ozone. Colloids Surf, B. 2004 May 01;35(1):1-5. DOI:10.1016/j.colsurfb.2004.01.005. PubMed PMID: 15261048.

[12] Yang Z, Wang J, Luo R, et al. The covalent immobilization of heparin to pulsed-plasma polymeric allylamine films on 316L stainless steel and the resulting effects on hemocompatibility. Biomaterials. 2010 Mar;31(8):2072-2083. DOI:10.1016/j.biomaterials.2009.11.091. PubMed PMID: 20022107.

[13] Olsson P, Sanchez J, Mollnes TE, et al. On the blood compatibility of end-point immobilized heparin. J Biomater Sci Polym Ed. 2000;11(11):1261-1273. DOI:10.1163/156856200744192

[14] Han DK, Lee NY, Park KD, et al. Heparin-like anticoagulant activity of sulphonated poly(ethylene oxide) and sulphonated poly(ethylene oxide)-grafted polyurethane. Biomaterials. 1995;16(6):467-471.

[15] Lin W-C, Liu T-Y, Yang M-C. Hemocompatibility of polyacrylonitrile dialysis membrane immobilized with chitosan and heparin conjugate. Biomaterials. 2004;25(10):1947-1957. DOI:10.1016/j.biomaterials.2003.08.027

[16] Lin WC, Tseng CH, Yang MC. In-vitro hemocompatibility evaluation of a thermoplastic polyurethane membrane with surface-immobilized water-soluble chitosan and heparin. Macromol Biosci. 2005 Oct 20;5(10):1013-1021. DOI:10.1002/mabi.200500077. PubMed PMID: 16211549.

[17] Du JR, Peldszus S, Huck PM, et al. Modification of poly(vinylidene fluoride) ultrafiltration membranes with poly(vinyl alcohol) for fouling control in drinking water treatment. Water Res. 2009 Oct;43(18):4559-4568. DOI:10.1016/j.watres.2009.08.008. PubMed PMID: 19716151.

[18] Baumann H, Kokott A. Surface modification of the polymers present in a polysulfone hollow fiber hemodialyser by covalent binding of heparin or endothelial cell surface heparan sulfate: flow characteristics and platelet adhesion. J Biomater Sci Polym Ed. 2000;11(3):245-272. DOI:10.1163/156856200743689

[19] Douzon C, Kanmangne F, Serne H, et al. Heparin-like activity of insoluble sulphonated polystyrene resins Part III: binding of dicarboxylic amino acids. Biomaterials. 1987;8(3):190-194.

[20] Pillai CKS, Paul W, Sharma CP. Chitin and chitosan polymers: chemistry, solubility and fiber formation. Prog Polym Sci. 2009;34(7):641-678. DOI:10.1016/j.progpolymsci.2009.04.001

[21] Rinaudo M. Chitin and chitosan: properties and applications. Prog Polym Sci. 2006;31(7):603632. DOI:10.1016/j.progpolymsci.2006.06.001

[22] Sashiwa H, Aiba S-I. Chemically modified chitin and chitosan as biomaterials. Prog Polym Sci. 2004;29(9):887-908. DOI:10.1016/j.progpolymsci.2004.04.001 
[23] Silva TH, Alves A, Ferreira BM, et al. Materials of marine origin: a review on polymers and ceramics of biomedical interest. Int Mater Rev. 2013;57(5):276-306. DOI:10.1179/174328041 2y.0000000002

[24] Madihally SV, Matthew HW. Porous chitosan scaffolds for tissue engineering. Biomaterials. 1999;20(12):1133-1142.

[25] Zhao QS, Ji QX, Xing K, et al. Preparation and characteristics of novel porous hydrogel films based on chitosan and glycerophosphate. Carbohyd Polym. 2009;76(3):410-416. DOI:10.1016/j. carbpol.2008.11.020

[26] Samet Y, Kraiem D, Abdelhédi R. Electropolymerization of phenol, o-nitrophenol and o-methoxyphenol on gold and carbon steel materials and their corrosion protection effects. Prog Org Coat. 2010;69(4):335-343.

[27] Wang J, Chen S-P, Lin MS. Use of different electropolymerization conditions for controlling the size-exclusion selectivity at polyaniline, polypyrrole and polyphenol films. J Electroanal Chem Interfacial Electrochem. 1989;273(1-2):231-242.

[28] Kocaçalışkan I, Talan I, Terzi I. Antimicrobial activity of catechol and pyrogallol as allelochemicals. Z für Naturforsch C. 2006;61(9-10):639-642.

[29] Harris TM, Whitney GM, Croll IM. The electrodeposition of Ni-Fe-Cr alloys for magnetic thin film applications. J Electrochem Soc. 1995;142(4):1031-1034.

[30] Chen S, Liu T, Yin Y. Stable biomimetic film on Fe3Al surface for corrosion resistance in seawater. Sci China Ser E: Technol Sci. 2008;51(7):975-978. DOI:10.1007/s11431-008-0071-3.

[31] Ignatova M, Voccia S, Gabriel S, et al. Stainless steel grafting of hyperbranched polymer brushes with an antibacterial activity: synthesis, characterization, and properties. Langmuir. 2008;25(2):891-902.

[32] Behpour M, Ghoreishi SM, Salavati-Niasari M, et al. Evaluating two new synthesized S-N Schiff bases on the corrosion of copper in 15\% hydrochloric acid. Mater Chem Phys. 2008;107(1):153157. DOI:10.1016/j.matchemphys.2007.06.068

[33] Zhu G, Huang X, Hojamberdiev M, et al. Preparation of Sb2S3 film on functional organic self-assembled monolayers by chemical bath deposition. J Mater Sci. 2010;46(3):700-706. DOI:10.1007/s10853-010-4797-5.

[34] Yuan SJ, Pehkonen SO, Ting YP, et al. Inorganic-organic hybrid coatings on stainless steel by layer-by-layer deposition and surface-initiated atom-transfer-radical polymerization for combating biocorrosion. ACS Appl Mater Interfaces. 2009 Mar;1(3):640-652. DOI:10.1021/ am800182d. PubMed PMID: 20355986.

[35] Chen Y, Chen S, Chen Y, et al. Surface analysis and electrochemical behaviour of the selfassembled polydopamine/dodecanethiol complex films in protecting 304 stainless steel. Sci Chin Technol Sci. 2012;55(6):1527-1534. DOI:10.1007/s11431-012-4788-7.

[36] Tao Y, Yi D, Zhu B, et al. Direct hydrothermal electrochemical preparation of diamond-like carbon films on substrates. J Mater Sci. 2010;46(4):1136-1138. DOI:10.1007/s10853-010-5069-0.

[37] Du JR, Peldszus S, Huck PM, et al. Modification of poly(vinylidene fluoride) ultrafiltration membranes with poly(vinyl alcohol) for fouling control in drinking water treatment. Water Res. 2009;43(18):4559-4568.

[38] Yuan SJ, Xu FJ, Pehkonen SO, et al. Grafting of antibacterial polymers on stainless steel via surface-initiated atom transfer radical polymerization for inhibiting biocorrosion by Desulfovibrio desulfuricans. Biotechnol Bioeng. 2009 Jun 01;103(2):268-281. DOI:10.1002/ bit.22252. PubMed PMID: 19170239.

[39] Yuan JP, Li W, Wang C. Effect of the La alloying addition on the antibacterial capability of 316L stainless steel. Mater Sci Eng: C. 2013 Jan 01;33(1):446-452. DOI:10.1016/j.msec.2012.09.012. PubMed PMID: 25428094.

[40] Lima PH, Pereira SV, Rabello RB, et al. Blood protein adsorption on sulfonated chitosan and $\kappa$-carrageenan films. Colloids Surf, B. 2013 Nov;111(111):719-725. DOI:10.1016/j. colsurfb.2013.06.002. PubMed PMID: 23911741.

[41] McKetta JJ Jr. Encyclopedia of chemical processing and design[M]. CRC Press; 1997.

[42] Zhang W, Li G, Fang Y, et al. Maleic anhydride surface-modification of crosslinked chitosan membrane and its pervaporation performance. J Membr Sci. 2007;295(1-2):130-138. 
[43] Juan AS, Montembault A, Gillet D, et al. Degradation of chitosan-based materials after different sterilization treatments. IOP Conf Ser: Mater Sci Eng. 2012;31(1):1-5. DOI:10.1088/1757$899 X / 31 / 1 / 012007$.

[44] Tangpasuthadol V, Pongchaisirikul N, Hoven VP. Surface modification of chitosan films. Carbohyd Res. 2003;338(9):937-942. DOI:10.1016/s0008-6215(03)00038-7.

[45] Nan L, Cheng J, Yang K. Antibacterial behavior of a Cu-bearing type 200 stainless steel. J Mater Sci \& Technol. 2012;28(11):1067-1070.

[46] Xue J, Zhao W, Nie S, et al. Blood compatibility of polyethersulfone membrane by blending a sulfated derivative of chitosan. Carbohyd Polym. 2013 Jun 05;95(1):64-71. DOI:10.1016/j. carbpol.2013.02.033. PubMed PMID: 23618240.

[47] Zhang W, Li G, Fang Y, et al. Maleic anhydride surface-modification of crosslinked chitosan membrane and its pervaporation performance. J Membr Sci. 2007;295(1-2):130-138. DOI:10.1016/j.memsci.2007.03.001.

[48] Lima PH, Pereira SV, Rabello RB, et al. Blood protein adsorption on sulfonated chitosan and к-carrageenan films. Colloids Surf, B. 2013;111:719-725.

[49] Zhang Z, Zhang M, Chen S, et al. Blood compatibility of surfaces with superlow protein adsorption. Biomaterials. 2008 Nov;29(32):4285-4291. DOI:10.1016/j.biomaterials.2008.07.039. PubMed PMID: 18722010.

[50] Kochkodan V, Hilal N. A comprehensive review on surface modified polymer membranes for biofouling mitigation. Desalination. 2015;356:187-207.

[51] Hedberg Y, Wang X, Hedberg J, et al. Surface-protein interactions on different stainless steel grades: effects of protein adsorption, surface changes and metal release. J Mater Sci: Mater Med. 2013 Apr;24(4):1015-1033. DOI:10.1007/s10856-013-4859-8. PubMed PMID: 23378148; PubMed Central PMCID: PMC3620448.

[52] Gottenbos B, Grijpma DW, van der Mei HC, et al. Antimicrobial effects of positively charged surfaces on adhering Gram-positive and Gram-negative bacteria. J Antimicrob Chemother. 2001;48(1):7-13.

[53] Kim CH, Choi KS. Synthesis and antibacterial activity of quaternized chitosan derivatives having different methylene spacers. J Ind Eng Chem. 2002;8(1):71-76. 